\title{
MEMÓRIAS DA DOR \\ A ESCRITA COMO UM TERRITÓRIO DE LIBERTAÇÃO, EMPODERAMENTO E RESISTÊNCIA EM TROPICAL SOL DA LIBERDADE
}

\author{
Camila Marchesan Cargnelutti \\ Anselmo Peres Alós \\ UFSM/CAPES
}

RESUMO: Nesse artigo, analisa-se o romance Tropical sol da liberdade (1988), da escritora brasileira Ana Maria Machado, publicado no contexto pós-ditatorial brasileiro. Observamos alguns aspectos da protagonista, Lena, como mulher duplamente oprimida — por suas ideologias e por seu gênero. Investigamos também a tentativa de reconstrução pós-traumática de sua história e de sua identidade a partir da escrita literária. 0 romance proporciona uma leitura alternativa do contexto da ditadura civil-militar brasileira (1964-1985) a partir de uma visão feminina. Além disso, tanto a autora quanto a personagem rejeitam 0 silenciamento das vozes femininas, promovem um rompimento com o papel de subordinação historicamente reservado às mulheres e contribuem para a desconstrução da representação tradicional do gênero feminino, dentro e fora do campo literário.

PALAVRAS-CHAVE: Memória. Autoria feminina. Ditadura civil-militar brasileira.

\author{
MEMORIES OF PAIN \\ WRITING AS A TERRITORY OF LIBERATION, \\ EMPOWERMENT AND RESISTANCE IN TROPICAL SOL DA LIBERDADE
}

ABSTRACT: In this paper, we analyze Tropical sol da liberdade (1988), a novel from a Brazilian author Ano Maria Machado, published in the post-dictatorial context in Brazil. We observe some aspects of the novel's main protagonist, Lena, as a woman who suffers a double oppression — caused by her ideology and by her gender. We also seek to investigate the attempt of a post-traumatic reconstruction of her history and identity by using a literary writing. The novel provides an alternative reading of the Brazilian civil-military dictatorship (1964-1985) from a feminine point of view. Moreover, both the author and the character reject the silencing of women's voices, promoting a breakup with the subservient role historically reserved for females and contributing to the deconstruction of the traditional representation of women, within and outside the literary field.

KEYWORDS: Memory. Female authorship. Brazilian civil-military dictatorship.

Camila Marchesan Cargnelutti | camila.m.cargnelutti@gmail.com | é mestranda em Estudos Literários no Programa de Pós-Graduação em Letras da Universidade Federal de Santa Maria.

Anselmo Peres Alós |anselmoperesalos@gmail.com|é professor do Departamento de Letras Vernáculas e do Programa de Pós-Graduação em Letras da Universidade Federal de Santa Maria. 


\title{
MEMÓRIAS DA DOR \\ A ESCRITA COMO UM TERRITÓRIO DE LIBERTAÇÃO, EMPODERAMENTO E RESISTÊNCIA EM TROPICAL SOL DA LIBERDADE
}

\author{
Camila Marchesan Cargnelutti \\ Anselmo Peres Alós
}

\section{INTRODUÇÃO}

Historicamente, as mulheres sempre tiveram sua liberdade restringida e sua autonomia como sujeitos negadas ou desvalorizadas. Relegadas ao ambiente doméstico e privado, o "segundo sexo" foi excluído da vida pública, do acesso à educação formal, do trabalho remunerado e das decisões políticas e familiares, oprimido e silenciado das mais diversas formas. Por outro lado, conforme explica Simone de Beauvoir, os homens, desde os primórdios do patriarcado, julgaram de grande utilidade para seus interesses e pretensões "manter a muIher em estado de dependência", concentrando em suas mãos a autonomia e o poder e constituindo concretamente a mulher como o Outro. ${ }^{1}$ Resquícios dessa constituição do gênero feminino como alteridade, e da opressão histórica resultante disso, ainda podem ser percebidos atualmente, inclusive, na literatura, uma vez que tanto a crítica como a historiografia literária estão calcadas em discursos falocêntricos, resistentes em admitir a existência de vozes literárias com uma visão outra, dissonante, representativa dessa alteridade historicamente silenciada.

Em contextos marcados por ditaduras militares, como as que sangraram o continente latino-americano na segunda metade do século $X X$, as tentativas de silenciamento das vozes consideradas dissonantes tornam-se ainda mais insistentes e evidenciam a intenção de calar a alteridade política e ideológica. Esse contexto de repressão e arbitrariedades influencia a escrita de muitos autores e autoras latino-americanas, constituindo também matéria narrativa para Tropical sol da liberdade (1988), romance da escritora brasileira Ana MaBEAUVOIR, Simone de. O segundo sexo: fatos e mitos. Trad. Sérgio Milliet. 4. ed. São Paulo: Difusão
Europeia do Livro, 1970, p. 179. 
ria Machado. ${ }^{2}$ Neste artigo, abordaremos alguns aspectos relacionados principalmente à personagem Lena, como mulher duplamente oprimida — por suas ideologias políticas e por seu gênero - e à tentativa de reconstrução pós-traumática - de sua história e de sua identidade - através da escrita literária.

Ao dar voz, através da literatura, a grupos silenciados e marginalizados socialmente possibilita-se a narração histórica e literária a partir de outros e novos ângulos, contribuindo para o resgate de outros lados da ditadura civilmilitar brasileira, para o preenchimento de lacunas não contempladas pela história oficial e para a emergência de versões sobre aquilo que o discurso oficial procurou calar ou ocultar. Nesse sentido, as histórias contadas por mulheres trazem à tona novos ângulos de enunciação, apresentando uma leitura alternativa da história, muitas vezes em confronto com a história oficial.

Nesse caso, além da autora, Ana Maria Machado, a própria personagem principal do romance, Lena, deseja escrever uma obra literária que fale de suas memórias e de outras versões da história a partir da "visão da periferia" ( $p$. 33), como ela autodenomina sua posição como mulher em um contexto ditatorial. Ao longo do livro, é possível perceber diversas marcas da repressão e da opressão perpetuada durante a ditadura brasileira e, particularmente, direcionada às mulheres em uma sociedade patriarcal, representando a duplicidade da opressão sofrida pelas mulheres no período - política e de gênero.

\section{LEMBRAR O TRAUMA: NECESSIDADE E SOFRIMENTO}

Em sua obra, Ana Maria Machado aborda o contexto da última ditadura civil-militar brasileira (1964-1985), a partir da história de Helena Maria de Andrade, a Lena, uma mulher que busca reconstruir sua vida após o exílio. Ao longo da obra, buscando recompor sua própria trajetória, a personagem recorda momentos históricos brasileiros do período ditatorial e percebe que a sua memória está intrinsecamente ligada à história do país. A obra de Ana Maria Machado procura recontar, como o próprio subtítulo diz, "a história dos anos de repressão e da juventude brasileira pós-64 na visão de uma mulher". Publicado em 1988, três anos após o fim da ditadura brasileira, Tropical sol da

2 MACHADO, Ana Maria. Tropical sol da liberdade. Rio de Janeiro: Nova Fronteira, 1988. Os trechos citados serão referenciados entre parênteses após as citações. 
liberdade traz em suas páginas, de maneira muitas vezes sutil e emocionante, momentos fundamentais da história do período repressivo no país pelo olhar do outro historicamente silenciado, assumindo um duplo papel de resistência e questionamento à ditadura civil-militar brasileira e ao sistema patriarcal que tem deslegitimado a voz das mulheres ao longo da história.

No romance, Lena, jornalista e escritora, encontra-se em um momento de crise e procura a proteção da mãe e da casa da infância em uma tentativa de recuperar o prumo e "encontrar-se". Exilada durante a ditadura civil-militar brasileira por sua militância política, a personagem apresenta em seu corpo e em sua mente vestígios desse passado traumático e repressivo, que podem ser percebidos em diversas passagens da obra. Ao recolher-se à casa materna, Lena rememora constantemente o passado e alimenta o desejo de escrever parte de suas memórias através de uma peça de teatro. No entanto, a personagem está, momentaneamente, impossibilitada de fazê-lo, por lapsos - que não são totalmente esclarecidos no romance - no equilíbrio, na fala e na escrita. Conforme a definição de Rosani Umbach, a personagem encontrase "enferma da palavra" ${ }^{3}$, não conseguindo, no presente da narrativa, expressar por meio da escrita suas lembranças, seus traumas e suas dores.

Essas dores, mais do que memórias conscientes de um passado recente, são sentidas em todo o corpo da personagem, podendo estar relacionadas também ao atual estado de desequilíbrio físico de Lena, que apresenta quedas constantes e está fazendo um tratamento medicinal para o distúrbio. O estado de Lena pode ser relacionado à "memória corporal" - "o corpo como repositório da memória de experiências traumáticas":

Falar em memórias da repressão implica, pois, referir-se não apenas a uma memória mental, desde sempre associada à consciência, ao caráter retrospectivo das lembranças e a conscientização voluntária do ocorrido; implica sobretudo referir-se a uma 'memória corporal', a qual abrange, na formulação de Aleida Assmann (1999), aquelas lembranças que não estão à disposição do livre arbítrio e por isso não podem ser manipuladas de acordo com a própria vontade. O corpo surge, então, como metáfora, como repositório da memória de experiências traumáticas. Fala-se de trauma quando uma lembrança armazenada pelo corpo está totalmente desvinculada da consciência: seria uma experiência corporalmente encapsulada, a qual se exprime através de sintomas e

3 UMBACH, Rosani Ketzer. Memórias autobiográficas em narrativas pós-ditatoriais. Letras de hoje, Porto Alegre, v. 48, n. 4, out./dez. 2013, p. 477. 
se subtrai a uma evocação recuperadora. ${ }^{4}$

Logo no início de Tropical sol da liberdade, o narrador nos apresenta Helena como "apenas uma mulher machucada que precisava se fechar numa toca e ficar passando a língua nas feridas até cicatrizarem" (p. 12). As razões para o corpo machucado da personagem vão sendo delineadas ao longo da narrativa e envolvem, dentre outras, os traumas do exílio recente e o término de seu casamento. Lena sofre física e psicologicamente, e seu corpo é representado como um repositório dessas lembranças - tanto sua mente quanto seu corpo guardam a memória dos traumas e das dores do passado. Abaixo podemos observar alguns excertos onde essas relações são exemplificadas:

Sei que, muito provavelmente, eu estou caindo porque não estou conseguindo me manter de pé diante do que está acontecendo. Fico humilhada, arrasada, prostrada, sei lá... (p. 55)

Deixar vir as lembranças, peneirar, separar, implicava necessariamente sentir dor de novo. E encarar de frente. Agora, por exemplo, deitada no escuro, fingindo que queria dormir, fingindo mais ainda, que não conseguia porque havia uns barulhos lá fora, Lena não podia mais fazer de conta que não ouvia os barulhos lá de dentro. E não eram só as lembranças das passeatas e dos dias jovens da ditadura, evocados pela conversa com a mãe. Essas eram as lembranças que ela catava e espalhava por cima do terreno, para disfarçar a areia ardente em que não queria pisar. Mas por baixo queimava, e ela sabia. (p. 114)

Sentiu as asas do nariz arderem um pouco, das lágrimas que se formavam e ela não queria chorar. Engoliu saliva com dificuldade, parecia que o que tinha que descer não ia passar pela garganta. E o peito continuava apertando, fechando, como se fosse esmagá-la. E talvez fosse melhor assim, se entregar, deixar que a dor a triturasse e acabasse de uma vez por todas com tudo aquilo... As lágrimas escorriam, os soluços se formavam, não queria sacudir os ombros, emitir sons, lutava para não gemer, reter qualquer movimento, impedir que as cordas vocais vibrassem. (p. 211)

A personagem encontra-se em um impasse em sua trajetória: deseja esquecer as memórias dos traumas e, simultaneamente, sente a necessidade de relembrar o passado traumático e escancarar a dor - "e era principalmente da dor que ela precisava falar" (p. 162); "[E]ra demais. Lena não aguentaria continuar, sabia bem. O exílio acabou, a dureza acabou, o casamento acabou. 4 UMBACH, Rosani Ketzer. Memórias da repressão e literatura: algumas questões teóricas. In:
(Org.). Memórias da repressão. Santa Maria: UFSM/PPGL-Editores, 2008, p. 18. 
Mas a dor continuava lá dentro, firme" (p. 210). Diante de tal situação, a personagem busca a escrita de uma peça de teatro como um recurso para falar de seus traumas e, de certa forma, lembrar e esquecer a dor.

De acordo com Márcio Seligmann-Silva, o sobrevivente de eventos traumáticos deseja, através de seu relato, "não apenas gerar memória (e, se possível justiça), mas também gerar o seu esquecimento." ${ }^{5}$ Nesse sentido, a partir do seu testemunho, Lena buscaria, além da memória e narração do trauma, uma espécie de esquecimento, no sentido de afastamento da dor. Para Seligmann-Silva, as vítimas necessitam "narrar, elaborar e esquecer" seus traumas e "querem se esquecer porque são assombradas pelo sofrimento desses males e não para apagar as atrocidades e, muito menos, negar um sentimento de justiça." 6

O impasse em que se encontra Lena, entre o desejo de lembrar e de esquecer, é agravado na narrativa de Tropical sol da liberdade, uma vez que a personagem está momentaneamente com um distúrbio em seu equilíbrio e, possivelmente por conta da medicação que toma para o tratamento, apresenta dificuldade e, muitas vezes, impossibilidade de escrever - "como tecer frases se o fio das palavras se rompe a toda hora, como carretilha quebrada na máquina de costura, embolando a linha e mordendo em seco?" (p. 82) Esse distúrbio, por sua vez, conforme abordamos anteriormente, pode ser entendido como uma consequência do passado traumático da personagem, que guarda em sua mente e em seu corpo as memórias da dor.

Por conta da doença, Lena encontra-se constantemente com "medo de cair" - "faltava era coragem para experimentar e ousar dar o salto no escuro. Medo de voltar a cair. E não levantar mais" (p. 82); "faço qualquer coisa para não cair mais" (p. 84); "por favor, não insista. A ideia de ficar caindo me dá pânico. Não tenho condições" (p. 85); "mas se eu cair, quem cai sou eu, não é? Como se o senhor me animasse a atravessar uma pontezinha em cima de um abismo. Mas não é o senhor que atravessa... E se eu cair?" (p. 85) Nos trechos acima, pode-se perceber que a personagem sente medo de perder o prumo, desequilibrar-se, cair novamente e não mais conseguir erguer-se e, ao mesmo tempo, visualiza as possibilidades que parar com a medicação para esse transtorno pode trazer, no que se refere a sua capacidade de voltar a ter domínio

\footnotetext{
5 SELIGMANN-SILVA, Márcio. Direito pós-fáustico: por um novo tribunal como espaço de rememoração e elaboração dos traumas sociais. In: CORNELSEN, Élcio Loureiro, et al. (Orgs.). Literatura e cinema de resistência. Rio de Janeiro: Oficina Raquel, 2013, p. 133.

6 Ibidem, p. 134.
} 
sobre sua fala e sua escrita - sobre suas palavras. Nesse sentido, do outro lado, como "recompensa" por enfrentar o abismo, estaria a escrita da peça de teatro baseada em suas memórias do exílio:

\begin{abstract}
O pior era que do outro lado do abismo e da ponte estreita e perigosa também estava o embrião da peça e de todos os textos futuros. Impossível tentar escrever nessas condições. Lena sentia que mais cedo ou mais tarde ia ter que se decidir de uma vez por todas. Ou desistia de escrever, ou se arriscava a despencar. Mas ainda não tinha coragem. (p. 86)
\end{abstract}

No entanto, para alcançar o "outro lado do abismo" e poder colocar em palavras suas memórias, seria preciso também encarar suas dores, recordar seus traumas, abrir-se para os outros através das letras. São esses os passos que Lena procura encontrar coragem e forças para dar, mas depara-se sempre com o medo de cair e o medo de rememorar, por todo o sofrimento que seu passado traumático ainda lhe traz - "o que ficava muito complicado era qualquer tentativa de botar para fora, de passar para as palavras, de tentar a viagem de dentro de si mesma para o outro [...]. Não conseguia. Mesmo falar, já era muito difícil. Escrever, então, no momento nem pensar" (p. 127).

Assim, a personagem encontra-se impossibilitada de escrever, com dificuldade de falar e, muitas vezes, com medo de rememorar. Consciente de seu estado atual, quando busca a proteção e a segurança da casa da infância, da mãe e da amendoeira do quintal para superar suas crises, Lena faz questão de não levar a máquina de escrever. No entanto, não consegue desfazer-se das visões, do delírio, da memória, do sonho e do pesadelo, carregados dentro de si mesma, como memória do corpo e da mente. Ao longo do romance, mesmo impossibilitada de transpor em palavras suas experiências traumáticas, Lena vê a escrita como um recurso para elaborar, lembrar e esquecer as memórias dolorosas. O desejo de escrever uma peça de teatro, já iniciada, que aborde algumas das experiências vividas no exílio, representa uma possibilidade de compartilhar, através das palavras, seu mundo interior com os outros. Nesse sentido, as palavras são uma espécie de "salvação" - de "ponte", de "páraquedas" - para a personagem, como é possível observar, por exemplo, no seguinte fragmento: "até mesmo as palavras que iam ser a ponte, o pára-quedas para o salto no escuro, já estavam lá dentro também, embriões de frases, expressões gestadas, floração, germinando" (p. 128-129). 


\title{
A MEMÓRIA E A ESCRITA: TERRITÓRIOS DE LIBERDADE PESSOAL
}

Ana Maria Machado, através de sua narrativa, dá voz a um grupo social historicamente silenciado e marginalizado, possibilitando a abordagem de processos históricos, tal como o ditatorial brasileiro, por um viés não contemplado pelos discursos hegemônicos e pela história oficial - Lena, de acordo com o narrador, deseja contar suas experiências e vivências relacionadas à ditadura a partir da "visão da periferia" (p. 33). Em contextos repressivos, o silenciamento e a exclusão reservada às mulheres são ainda mais acirrados, e suas histórias frequentemente são distorcidas, manipuladas e ocultadas por discursos oficiais, como explica Jaime Ginzburg:

\begin{abstract}
Segmentos sociais excluídos por forças repressoras, muitas vezes, tiveram suas vivências relatadas por discursos oficiais de modos distorcidos, restritivos ou manipulados. Grupos reificados pela escravidão, por preconceitos e por violência institucional, muitas vezes, não tiveram a devida oportunidade de apresentar seus pontos de vista sobre as transformações históricas. Tratados como objetos do conhecimento oficial, muitas vezes foram reduzidos a resíduos de si mesmo, tendo suas vivências ocultadas ou esquecidas, pelas narrativas contadas em linguagem autoritária por governos repressores e instituições disciplinares hostis. $^{7}$
\end{abstract}

Nesse contexto, onde se tenta impedir de diversas formas a emergência de discursos dissonantes, também desponta a tentativa de interromper processos de formação identitária de grupos vistos como o Outro, do ponto de vista do grupo de referência. As identidades, conforme Rita Schmidt, são como

movimentos contínuos/descontínuos das relações que sujeitos, comunidades, nações estabelecem imaginariamente com o outro, o que garante sua autoconstituição, e sua inserção dentro de certas condições sócio-históricas e discursivas $^{8}$

que, por sua vez, sustentam aquelas relações. Sobre as relações entre identidade e alteridade, Eric Landowski afirma que é a partir da alteridade que os sujeitos se identificam e se definem reciprocamente, construindo-se pela diferença. ${ }^{9}$ Assim, as subjetividades e representações simbólicas da identidade

7 GINZBURG, Jaime. Literatura e direitos humanos: notas sobre um campo de debates. In: UMBACH, Rosani Ketzer (Org.). Memórias da repressão, op. cit., p. 200.

8 SCHMIDT, Rita Terezinha. Em busca da história não contada ou: o que acontece quando o objeto começa a falar? Letras, Santa Maria, n. 16, jan./jun. 1998, p. 184.

9 Cf. LANDOWSKI, Eric. Presenças do outro: ensaios de sociossemiótica. São Paulo: Perspectiva, 2002. 
configuram-se como espaços da ideologia, explicando o interesse (reforçado em contextos repressores) dos grupos majoritários nesses processos de coação das vozes da alteridade. ${ }^{10}$

Nesses casos, como contraponto, o papel da memória sobressai-se como um lugar para a (re)construção identitária de grupos socialmente minoritários, conforme explica Rita Terezinha Schmidt:

\begin{abstract}
a memória, mais do que um simples arquivo classificatório de informação que reinventa o passado, é um referencial norteador na construção de identidades no presente. Em sua capacidade de manter e segurar o sentido, a memória atua por meio de seus efeitos, que tanto podem ser de lembrança e de renomeação, quanto de ruptura e de denegação do já-dito. Se a memória é, portanto, um fato essencial do processo cognitivo, inerente à construção de identidade, o discurso é o instrumento de (auto) conhecimento, através do qual o(s) ser(es) humano(s) se fazem sujeitos no campo da produção e das relações sociais. ${ }^{11}$
\end{abstract}

De acordo com o trecho supracitado, assim como a memória é essencial no processo de constituição de identidades, o discurso produzido pelos seres humanos é o instrumento por meio do qual eles se tornam sujeitos. Nesse sentido, a tentativa de apropriação da narrativa pela personagem Lena de Tropical sol da liberdade para falar desde outro ângulo da história ditatorial brasileira representa muito mais que uma forma de questionamento dos discursos oficiais e de resistência frente a eles. O desejo - e a necessidade - de Lena de escrever suas memórias é relatado em diversas passagens do romance, e representa, principalmente, uma possibilidade de contar uma história de silenciamento e desapropriação da voz feminina, desconstruindo a representação tradicional das mulheres e transformando-as em sujeitos de seus próprios discursos, de suas próprias identidades e de suas próprias histórias.

Segundo Regina Dalcastagnè, "reconstruir o vivido é refazer a história, recolocando nela personagens marginalizadas." Dessa forma, ocorre o que a pesquisadora chama de "dupla reabilitação": "refaz-se aí a história dos vencidos e, dentro dessa história, recompõe-se o lugar da mulher." ${ }^{12}$ Essa dupla reabilitação, através da obra literária, que também pode ser entendida como

${ }^{10}$ Cf. SCHMIDT, Rita Terezinha. Em busca da história não contada..., op. cit.

${ }^{11}$ Ibidem, p. 184-185.

12 DALCASTAGNĖ, Regina. O espaço da dor: o regime de 64 no romance brasileiro. Brasília: Ed. UnB, 1996, p. 114. 
um desejo de Lena ao narrar suas memórias da periferia, relaciona-se ao que Seligmann-Silva escreve sobre a narrativa de testemunho por meio da literatura:

A narrativa teria [...] esse desafio de estabelecer uma ponte com "os outros", de conseguir resgatar o sobrevivente do sítio da outridade, de romper com os muros do Lager [campo de concentração]. A narrativa seria a picareta que poderia ajudar a derrubar este muro. [...] Narrar o trauma, portanto, tem em primeiro lugar este sentido primário de renascer. ${ }^{13}$

Nesse processo vivenciado pela personagem, história, memória e literatura são inseparáveis e estão diretamente relacionadas à formação de identidades, tanto individuais quanto coletivas. Ao mesmo tempo em que vê na escrita a possibilidade de lembrar e esquecer os traumas, conforme abordamos anteriormente, pode-se perceber através da voz narrativa que Lena também apresenta aquilo que Seligmann-Silva chama de desejo de "renascer" do sobrevivente de eventos traumáticos, por meio do qual se manifesta seu anseio de reconstruir sua identidade e reconstituir-se enquanto sujeito. ${ }^{14}$

Em Tropical sol da liberdade, a protagonista está em um dos "momentos mais difíceis que já tinha vivido, insegura, à procura de si mesma" (p. 115) e sente que, de alguma forma, precisa encontrar forças e coragem para renascer, tal como uma fênix:

A menina Lena não sabia o que era fênix. Só foi saber mais tarde, quando cresceu. E a mulher Lena pensava consigo mesma que era isso mesmo o que ela precisava ser, uma fênix. Em algum momento, teria que fazer isso, renascer integral. Como a cobra que sai inteira da pele velha, deixa para trás a casca vazia, e brota de dentro de si mesma, nova, guardando aquilo que era essencialmente. Não como a borboleta que sai do casulo sem conservar nada da lagarta que tinha sido antes. Renascer sem metamorfose, fiel a si mesma. Um desafio permanente. $O$ de conseguir estar viva. (p. 234)

No excerto acima, observar-se o desejo de renascimento, de transformação e de renovação da protagonista da obra, apesar das - e com as - dores. Nesse processo de reconstituição do sujeito, no entanto, ressalta-se a necessi-

\footnotetext{
${ }^{13}$ SELIGMANN-SILVA, Márcio. Narrar o trauma: a questão dos testemunhos de catástrofes históricas. Psicologia Clínica, Rio de Janeiro, v. 20, n. 1, 2008, p. 66.

${ }^{14}$ Cf. Idem (Org.). História, memória, literatura: o testemunho na Era das Catástrofes. Campinas: Ed. Unicamp, 2003.
} 
dade de conservar aquilo que se é essencialmente, ser "fiel a si mesma", considerando também suas memórias traumáticas e as dores que lhe causam, uma vez que elas também são constituintes de sua identidade. Apesar do auxílio que os sujeitos com quem a personagem interage podem proporcionar, essa reconstituição identitária e, simultaneamente, a recuperação do corpo traumatizado, são processos essencialmente individuais, como pode ser percebido no seguinte trecho:

ia ter que se levantar, sozinha, sem muletas de remédios, enfrentando o risco, pagando para ver. Quando chegasse o momento em que se sentisse suficientemente forte, com um mínimo de segurança para ter um ponto de apoio onde se firmar e se converter em alavanca de si mesma. (p. 237)

As possibilidades de reconstruir-se como sujeito através da escrita também são apontadas por Rosani Umbach e Vera Vianna, que falam sobre a "possibilidade de cura" em análise da obra:

\footnotetext{
O desejo da protagonista de montar uma peça teatral é um aspecto reiterado em vários segmentos da narrativa, e aponta a necessidade de encenar as experiências violentas que testemunhou, configurando-se também, como uma possibilidade de cura - o anseio de abrir-se novamente para o mundo e desatar o nó que a amarra às memórias passadas de dor e sofrimento. ${ }^{15}$
}

Ao longo do romance percebe-se que, apesar da necessidade que a protagonista sente de narrar suas memórias, está momentaneamente com dificuldades por conta do distúrbio e pelas dores que as lembranças lhe trazem. Essa dificuldade de transpor em palavras as memórias traumáticas também poderia relacionar-se ao que Seligmann-Silva chama de oscilação entre uma necessidade e uma impossibilidade: "necessidade de narrar e a impossibilidade de esgotar com palavras suas vivências." ${ }^{16}$ Sobre a impossibilidade de colocar a dor e o sofrimento em palavras, Jaime Ginzburg explica que "na literatura é constante encontrar personagens que têm necessidades, carências, sofrimentos, e não encontram as palavras adequadas para formular o que precisam." ${ }^{17}$ Nessas situações, é como se existissem descontinuidades entre o pensamento e a linguagem, podendo surgir silêncios e omissões. O

\footnotetext{
${ }^{15}$ UMBACH, Rosani Ketzer e VIANNA, Vera Lucia Lenz. Memória, escrita e assimetria de poder em Tropical sol da liberdade. Letras, Santa Maria, v. 20, n. 41, jul./dez. 2010, p. 72.

${ }^{16}$ SELIGMANN-SILVA, Márcio. Direito pós-fáustico, op. cit., p. 133.

17 GINZBURG, Jaime. Literatura e direitos humanos, op. cit., p. 188.
} 
autor afirma ainda que, embora o sujeito não possa falar tudo, nem ser sempre compreendido, ele "deve achar condições para expressar suas demandas." ${ }^{18}$

Nesse sentido, é pela tentativa de escrita de uma peça de teatro que Lena procura elaborar, lembrar e esquecer seus traumas. No entanto, vive esse conflito entre a necessidade e a impossibilidade de narrar, tanto pela doença e pelo sofrimento que rememorar the provoca, física e psicologicamente, quanto pela dificuldade de transpor suas dores e suas memórias através das palavras:

O problema todo é que não tinha como compartilhar esse mundo interior sem as palavras. E as palavras fugiam dela com a doença. Ou com os remédios que impediam que o chão fugisse. Era como se em algum momento ela tivesse que escolher entre perder o prumo e perder a palavra. (p. 128)

Era uma questão - de qualquer modo, nada simples - de conseguir mergulhar no mundo com uma percepção plena, elaborar isso internamente, jogar tudo para fora de novo de uma forma bela. Para isso, trabalhar muito [...]. Mas Lena achava que, com as palavras, tudo fica de certa maneira mais complicado. (p. 160)

Ao mesmo tempo, a personagem manifesta também uma preocupação com a memória, tanto individual quanto coletiva, refletindo sobre a importância de recordar esse passado traumático, de dar seu testemunho através da literatura, de falar sobre as dores, como uma forma de evitar o esquecimento e a repetição desse tipo de violência no presente e no futuro. Por meio do narrador, vislumbra-se como até pensar nesse passado lhe causava sofrimento: "até hoje, Lena não podia pensar nisso sem sentir um aperto no peito, um nó na garganta, uma raiva impotente, uma dor inenarrável, uma vergonha imensa de fazer parte de uma nação em que coisas desse tipo aconteceram e nunca foram punidas" (p. 98).

Destaca-se ainda o papel que a escrita assume como um "território de liberdade pessoal" em Tropical sol da liberdade. No romance, a personagem busca apropriar-se da narrativa como um espaço de proteção, de libertação e de autonomia, como se vê nos seguintes fragmentos: "ela queria esculpir e cinzelar a pedra bruta da linguagem de todo dia [...] para construir uma morada que ajudasse a proteger a todos"; "sobretudo para si mesma, morada

\footnotetext{
18 Ibidem, p.188.
} 
que fosse um território seu, sem invasões"; "um dique contra a invasão, delimitando um território seu, de liberdade pessoal" (p. 43). Assim, ganha relevo a importância da palavra para a protagonista, principalmente como um meio de libertação e empoderamento, o que também fica explícito no trecho a seguir, em que Lena consegue enfrentar o autoritarismo do médico que fora consultar por conta de seu distúrbio:

[Orgulhosa] por não ter calado a boca diante do autoritarismo arrogante do professor. Era a primeira vez, em semanas, que conseguia enfrentar alguém [...] Não, alguma coisa lhe dizia que doença e morte era deixar que alguém a silenciasse e cassasse sua palavra e seu desejo, como o professor queria fazer. Afinal, era disso que estava enferma, era isso que tanto a incomodava, era para isso que buscara tratamento. Sentia que estava certa. Não era o queijo, era a fala. Viver sem a palavra não interessava. (p. 54)

No fragmento acima também se observa a necessidade que Lena sente de construir seu próprio discurso, de não se deixar silenciar por conta de autoritarismos e de recusar o papel de subordinação historicamente reservado às mulheres. Nesse sentido, Tropical sol da liberdade vai ao encontro do que Márcia Navarro fala sobre a literatura de autoria feminina na América Latina: "essas narrativas apresentam uma nova visão da mulher que, através da força da palavra escrita, ou através de uma forma contestadora de atuação no mundo, subverte os padrões comportamentais tradicionalmente exigidos ao 'segundo sexo'." ${ }^{19}$ Dessa forma, tanto a autora Ana Maria Machado quanto a própria protagonista do romance subvertem a representação tradicional do gênero feminino, construindo uma mulher/personagem como sujeito de seu próprio discurso, de sua identidade e de sua história.

\section{CONSIDERAÇÕES FINAIS}

Dar visibilidade a discursos literários historicamente escamoteados representa um passo muito importante para proporcionar uma maior pluralidade de histórias, além de promover uma valorização de vozes e de grupos socialmente minoritários e marginalizados. A literatura de autoria feminina e, particularmente a construção de personagens femininas, como no caso de

\footnotetext{
${ }^{19}$ NAVARRO, Márcia Hoppe. Por uma voz autônoma: o papel da mulher na história e na ficção latinoamericana contemporânea. In: ___. (Org.). Rompendo o silêncio: gênero e literatura na América Latina. Porto Alegre: Ed. UFRGS, 1995, p. 52.
} 
Tropical sol da liberdade, além de possibilitar a visão de processos históricos por um viés não contemplado pela história oficial (proporcionado novas versões, ângulos e olhares sobre o passado recente nacional), permite ressignificar a memória e a escrita literária como uma forma de duplo questionamento e de resistência - política e de gênero. Dessa maneira, abre-se um leque de novas maneiras de pensar o passado a partir da literatura de grupos silenciados e, particularmente, da autoria feminina.

Narrativas como a de Ana Maria Machado têm sua importância renovada ainda por transformar sua personagem, Lena, em sujeito de seu próprio discurso, de sua identidade e de sua história. Dessa forma, a autora promove um rompimento com o papel de subordinação historicamente reservado às mulheres, entendidas como espéculo da alteridade, em uma sociedade patriarcal. Tanto Ana Maria Machado quanto Lena rejeitam o silenciamento das vozes das mulheres - historicamente vistas como "o outro", o "segundo sexo", o "sexo frágil" - e contribuem para a subversão e para a desconstrução da representação tradicional do gênero feminino, dentro e fora do campo literário. 